\title{
Efficient Treatment of Phenol Wastewater by Catalytic Ozonation over Micron-Sized Hollow MgO Rods
}

Shanshan Zhang, ${ }^{\perp}$ Lilong Zhou, ${ }^{*}, \perp$ Zhengjie Li, Ali Asghar Esmailpour, Kunjie Li, Shuhuan Wang, Runjing Liu, Xiaoyan Li, and Jimmy Yun*

Cite This: ACS Omega 2021, 6, 25506-25517

Read Online

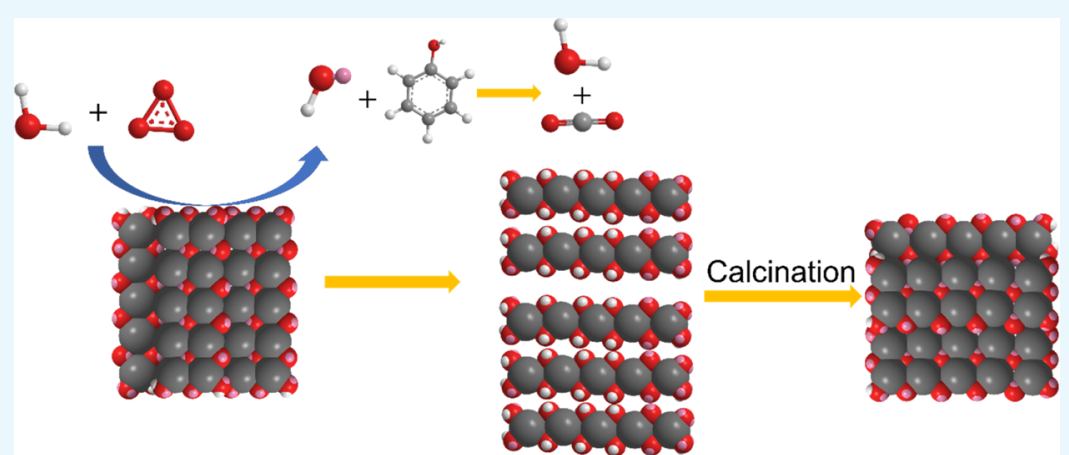

ABSTRACT: Phenol is a nocuous water pollutant that threatens human health and the ecological environment. CoO $\mathrm{x}_{\mathrm{x}}$-doped micron-sized hollow $\mathrm{MgO}$ rods were prepared for the treatment of phenol wastewater by catalytic ozonation. Magnesium sources, precipitants, initial precursor concentration, $\mathrm{Co} / \mathrm{Mg}$ molar ratio, and catalyst calcination temperature were optimized to obtain the best catalysts. Prepared catalysts were also well characterized by various methods to analyze their structure and physical and chemical properties. In this process, $\mathrm{CoO}_{\mathrm{x}} / \mathrm{MgO}$ with the largest large surface area $\left(151.3 \mathrm{~m}^{3} / \mathrm{g}\right)$ showed the best catalytic performance $(100$ and $79.8 \%$ of phenol and chemical oxygen demand (COD) removal ratio, respectively). The hydrolysis of $\mathrm{CoO}_{\mathrm{x}} / \mathrm{MgO}^{\mathrm{plays}}$ a positive role in the degradation of phenol. The catalytic mechanism of the degradation of $\mathrm{O}_{3}$ to free radicals over catalysts has been investigated by in situ electronic paramagnetic resonance (EPR). The catalyst can be reused at least five times without any activity decline. The prepared $\mathrm{CoO}_{\mathrm{x}} / \mathrm{MgO}$ catalyst also showed excellent catalytic performance for removal and degradation of ciprofloxacin, norfloxacin, and salicylic acid.

\section{INTRODUCTION}

Phenol, an important chemical, is widely used in the production of preservatives, fungicides, and drugs and is also an important product of coking industry. However, low concentrations of phenol have often been detected in industrial and surface water, which caused serious threats to the ecological environment and human health. Due to high toxicity and inertia, traditional treatment methods, such as biological and physical methods, are difficult to treat phenol and its derivatives effectively. ${ }^{1-6}$

Ozone is widely used in wastewater treatment, which can be decomposed into hydroxyl radicals and destroy various unsaturated carbon bonds. However, intermediates produced in the reaction can hinder ozone decomposition, so single ozone oxidation cannot completely degrade the organic matter and its intermediates efficiently. ${ }^{7}$ To overcome these drawbacks, catalysts have been applied to improve production of the hydroxyl radical in the reaction process. The hydroxyl radical has strong oxidizability and plays an important role in the degradation of organics. As known, the catalytic ozonation process can enhance mineralization efficiency by transforming ozone into more reactive hydroxyl radicals. The current catalysts studied for catalytic ozonation treatment of wastewater include $\mathrm{Fe}_{3} \mathrm{O}_{4} @ \mathrm{SiO}_{2} @ \mathrm{CeO}_{2},\left(\mathrm{MnO}_{2}-\mathrm{Co}_{3} \mathrm{O}_{4}\right) / \mathrm{AC}$, $\mathrm{MgMnO}_{3}, \mathrm{Mn} / \gamma-\mathrm{Al}_{2} \mathrm{O}_{3}$, etc. ${ }^{8-11}$ However, these catalysts have various disadvantages in the reaction, such as tedious synthesis, difficult recovery, ecumenic effect, and an unknown mechanism. ${ }^{12}$ Therefore, it is pivotal to find an efficient catalyst for the improvement of phenol wastewater treatment efficiency.

$\mathrm{MgO}$ has been used in catalytic ozonation due to its high activity, strong alkalinity, good stability, and environmental friendliness. Moussavi et al. have reported that $\mathrm{MgO}$ has good

Received: July 5, 2021

Accepted: September 6, 2021

Published: September 24, 2021 
activity in the treatment of Red 198 azo dye. However, the removal rate of chemical oxygen demand (COD) only reached about $60 \%$ with an initial Red 198 azo dye concentration of $200 \mathrm{mg} / \mathrm{L}$, an initial $\mathrm{pH}$ of 8 , and a $\mathrm{MgO}$ dosage of $5 \mathrm{~g} / \mathrm{L} .{ }^{13}$ $\mathrm{Zhu}$ et al. used $\mathrm{MgO}$ to decompose quinoline. The TOC removal rate can reach about $45 \%$ over $\mathrm{MgO}(0.2 \mathrm{~g} / \mathrm{L})$ with an initial $\mathrm{pH}$ of 6.8 and initial quinoline concentration of $20 \mathrm{mg} /$ $\mathrm{L}^{14}$ The catalytic performance of mono-MgO can hardly meet the requirements of industrial applications due to the large proportion of lattice oxygen and relatively few active sites. One effective way to overcome this drawback is doping a heteroatom into $\mathrm{MgO}$ to improve its catalytic activity. $\mathrm{MgO}$ modified by $\mathrm{S}$ showed impressive activity for the degradation of antibiotic tetracycline (TTC), in which the degradation rate of TTC increased from 20 to $90 \%$. MgO modified by C showed good performance for the removal of humic acid due to the increase of defects and improvement of electron transfer. ${ }^{15} \mathrm{MgO}$ has weak oxidizability. Doping of certain metal oxides may change their surface electrical and catalytic properties. ${ }^{15} \mathrm{CoO}_{\mathrm{x}}$ is an oxide with various valence states, which can provide oxygen vacancy for catalytic oxidation. $\mathrm{MgO}$ doped by $\mathrm{Co}_{3} \mathrm{O}_{4}$ showed excellent activity for the oxidation of ammonia to nitrogen with an ammonia nitrogen removal rate of $85.2 \%$ and gaseous nitrogen selectivity of $44.8 \% .{ }^{16}$ However, its low surface area $\left(28.55 \mathrm{~m}^{2} / \mathrm{g}\right)$ hindered the further improvement of catalytic activity. To improve the catalytic performance of $\mathrm{MgO}$, its surface area and oxidizability need to be further improved. $\mathrm{CoO}_{\mathrm{x}}$ exhibits high catalytic activities for Co oxidation. ${ }^{17,18} \mathrm{CoO}_{\mathrm{x}}$ may enhance the activity of $\mathrm{MgO}$ for catalytic ozonation.

In this work, the $\mathrm{CoO}_{\mathrm{x}}$-doped hollow micron-sized $\mathrm{MgO}$ rod with the highest surface area and efficient activity has been prepared for treatment of high content phenol wastewater by catalytic ozonation. A series of influence factors have been investigated to verify the efficiency of catalytic ozonation. It is interesting that the hydrolysis of $\mathrm{CoO}_{\mathrm{x}} / \mathrm{MgO}$ devoted a great contribution to catalytic ozonation. Various characterization methods have been applied to verify the catalytic mechanism. Finally, the stability and wide applicability of the catalyst were investigated.

\section{RESULTS AND DISCUSSION}

2.1. Characterization of Catalysts. 2.1.1. Crystalline Structures of Catalysts. Figure 1 shows the diffractions of $\mathrm{CoO}_{x}, \mathrm{MgO}, 2 \% \mathrm{CoO}_{\mathrm{x}} / \mathrm{MgO}$, and used $2 \% \mathrm{CoO}_{\mathrm{x}} / \mathrm{MgO}$. Several pronounced peaks at about 19.2, 38.2, 42.5, 62.2, and $78.5^{\circ}$ can be ascribed to the 001, 111, 200, 220, and 222 crystalline facets of $\mathrm{MgO}$. For the diffractions of $\mathrm{CoO}_{\mathrm{x}}$, peaks corresponding to $\mathrm{CoO}, \mathrm{Co}(\mathrm{OH})_{2}$, or $\mathrm{Co}_{3} \mathrm{O}_{4}$ can be observed (shown in Figure 1). However, peaks of $\mathrm{Co}$ and $\mathrm{Mg}$ species overlap in $\mathrm{CoO}_{x} / \mathrm{MgO}$. It suggests that $\mathrm{CoO}_{x}$ and $\mathrm{MgO}$ formed an oxide solid solution due to their similar oxide crystal structure, cation size, and coordination, which can form a solid solution over the entire range of compositions. ${ }^{21}$ The peak strength of $\mathrm{MgO}(200)$ and $\mathrm{MgO}(220)$ decreased after loading the $\mathrm{CoO}_{\mathrm{x}}$; it may due to the coverage of $\mathrm{CoO}_{\mathrm{x}}$. For patterns of used $2 \% \mathrm{CoO}_{\mathrm{x}} / \mathrm{MgO}$, peaks belonging to $\mathrm{Co}(\mathrm{OH})_{2}, \mathrm{Mg}$ $(\mathrm{OH})_{2}, \mathrm{MgO}$, or $\mathrm{CoO}$ can be found. It indicates that $\mathrm{Mg}(\mathrm{OH})_{2}$ was generated from the hydration of $\mathrm{MgO}$. As seen in the overall view of Figure 1, doping $\mathrm{CoO}_{x}$ has little influence on the size of $\mathrm{MgO}$. The regenerated catalyst is shown in Figure S2; it can be seen that the catalyst was regressed to $\mathrm{MgO}$ after regeneration.

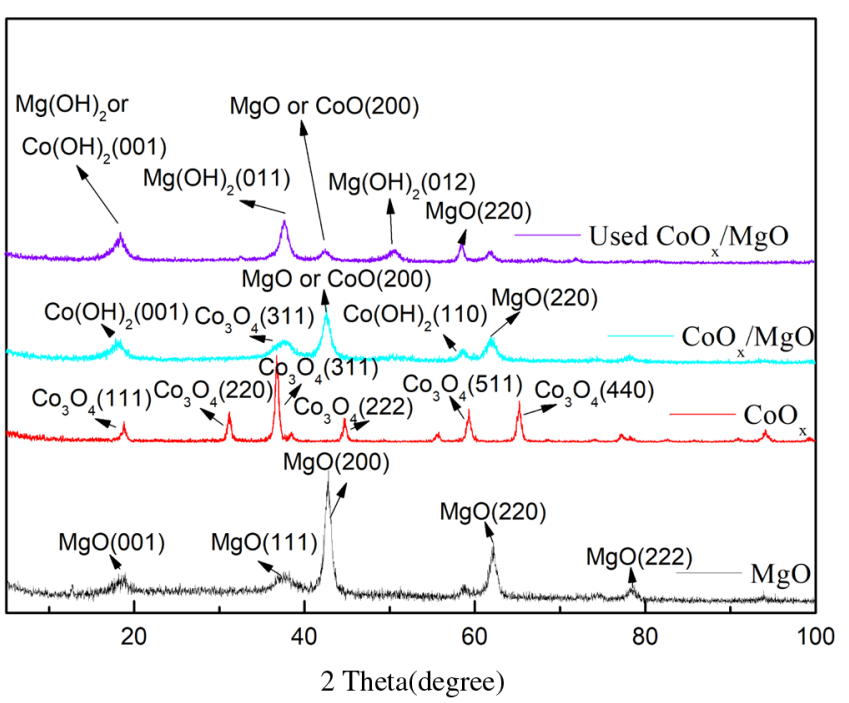

Figure 1. X-ray diffraction (XRD) patterns of the prepared $\mathrm{CoO}_{x}$ $\mathrm{MgO}, 2 \% \mathrm{CoO}_{\mathrm{x}} / \mathrm{MgO}$, and used $2 \% \mathrm{CoO}_{\mathrm{x}} / \mathrm{MgO}$.

2.1.2. Morphologies and Crystalline Structures of Catalysts. Scanning electron microscopy (SEM) and transmission electron microscopy (TEM) images of $\mathrm{CoO}_{\mathrm{x}} / \mathrm{MgO}$, and used and regenerated $\mathrm{CoO}_{\mathrm{x}} / \mathrm{MgO}$ are shown in Figure 2. Figure $2 \mathrm{a}$ shows that the catalyst presented a hollow rod structure with a length of 5-20 $\mu \mathrm{m}$ and a width of $0.5-5 \mu \mathrm{m}$. Some porous particles can be found on the hollow rod, which can correspond to $\mathrm{CoO}_{\mathrm{x}}$. It indicates that some $\mathrm{CoO}_{\mathrm{x}}$ was loaded on the surface of $\mathrm{MgO}$. However, it is hard to determine whether Co atoms entered the crystal structure of $\mathrm{MgO}$ by SEM, so TEM was performed. As can be seen in Figure $2 \mathrm{e}$, the crystals with lattice distances of 0.472 and 0.248 $\mathrm{nm}$ can correspond to $\mathrm{CoO}_{\mathrm{x}}(111)$ and $\mathrm{MgO}(111)$, respectively. $^{22,23}$ Two stripes with different lattice distances also indicate the crystal including two different metal atoms; Co binds to $\mathrm{MgO}$ by atom substitution. The results demonstrate that $\mathrm{CoO}_{\mathrm{x}}$ and $\mathrm{MgO}$ formed a solid solution, which is also proved by XRD. After the reaction, the catalyst was washed and dried and became rod constituted by sheet solid (as shown in Figure 2b). It suggests some $\mathrm{MgO}$ was hydrated to form $\mathrm{Mg}(\mathrm{OH})_{2}$, which is in accordance with XRD results. Figure 2c suggests that the recovered catalyst was regenerated after calcination and form a rodlike structure again. It indicates that the catalysts can be recovered by calcination. Figure 2e shows that the rodlike structure is mainly the crystal for the graph of electron diffraction of electron diffraction, suggesting the completion of particle crystallization (Figure 2e). The change of surface morphology in $\mathrm{CoO}_{\mathrm{x}} / \mathrm{MgO}$ plays a positive role in the degradation of organic matter during ozonation, which will be discussed in this work. ${ }^{5}$

2.1.3. Surface Areas and Pore Structures of Catalysts. Surface areas and pore structures of $\mathrm{MgO}, \mathrm{CoO}_{\mathrm{x}} / \mathrm{MgO}$, and used and regenerated $\mathrm{CoO}_{\mathrm{x}} / \mathrm{MgO}$ were characterized by nitrogen physical adsorption/desorption measurements. As illustrated in Figures S3 and S4, the samples show typical IV isotherms with hysteresis loops, which can be attributed to the mesoporous structure of catalysts. ${ }^{24}$ The surface areas of $\mathrm{MgO}$ and $2 \% \mathrm{CoO}_{\mathrm{x}} / \mathrm{MgO}$ (Table 1 ) were about 144 and $151 \mathrm{~m}^{2} / \mathrm{g}$, respectively. The results suggest that the addition of $\mathrm{CoO}_{\mathrm{x}}$ into $\mathrm{MgO}$ can increase the surface area of catalysts. The introduction of $\mathrm{Co}$ species combined with $\mathrm{Mg}$ species may 

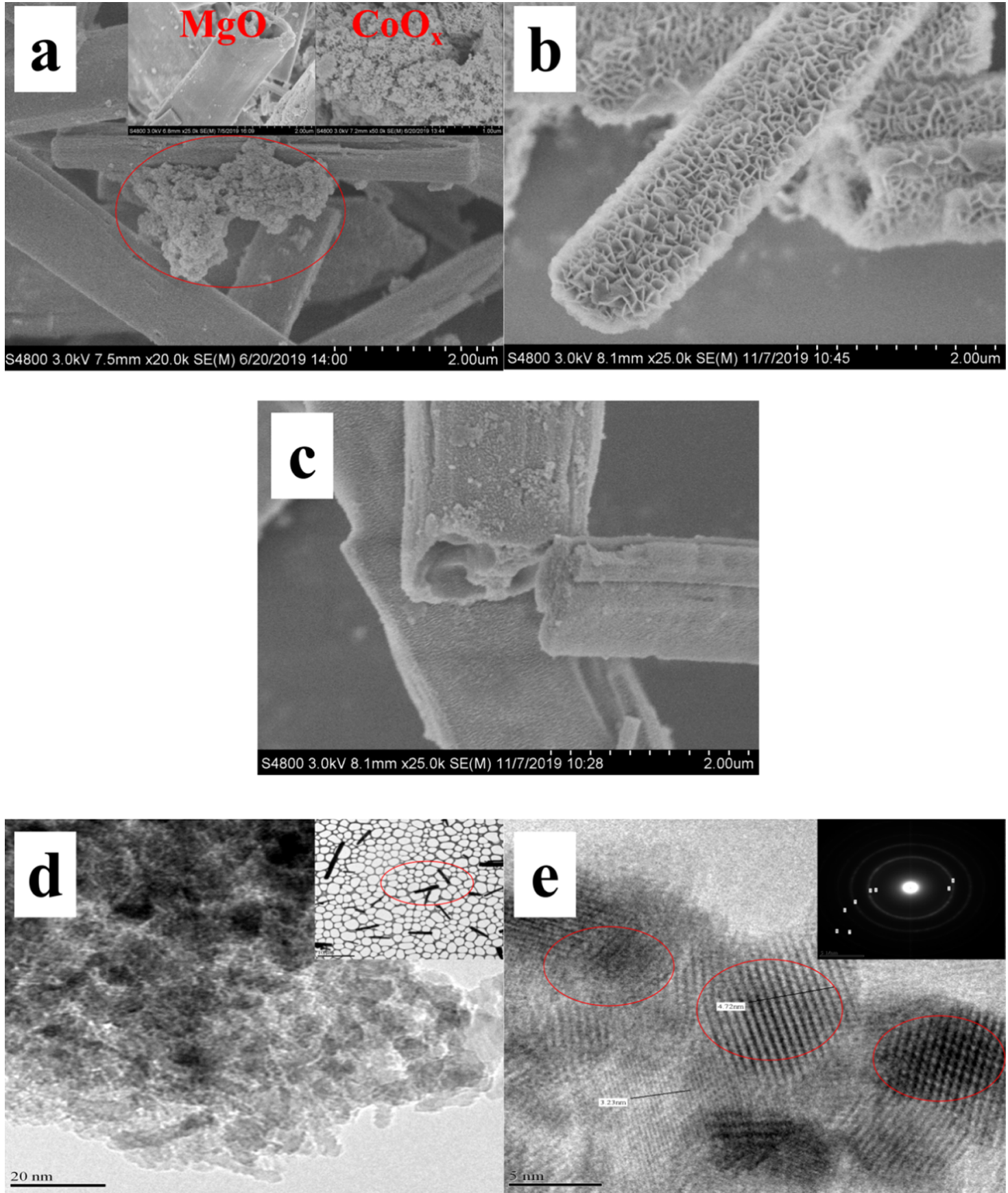

Figure 2. (a) SEM image of the prepared $2 \% \mathrm{CoO}_{\mathrm{x}} / \mathrm{MgO}$. (b) SEM image of the used $2 \% \mathrm{CoO}_{\mathrm{x}} / \mathrm{MgO}$. (c) SEM image of regenerated $2 \% \mathrm{CoO}_{\mathrm{x}} /$ $\mathrm{MgO}$. (d), (e) TEM images of the prepared $2 \% \mathrm{CoO}_{\mathrm{x}} / \mathrm{MgO}$.

Table 1. Brunauer-Emmett-Teller (BET) Analysis Results of Catalysts

\begin{tabular}{|c|c|}
\hline samples & BET surface area $\left(\mathrm{m}^{2} / \mathrm{g}\right)$ \\
\hline $\mathrm{MgO}\left(\mathrm{NH}_{3} \mathrm{H}_{2} \mathrm{O}\right)$ & 67 \\
\hline $\mathrm{MgO}(\mathrm{NaOH})$ & 45 \\
\hline $\mathrm{MgO}\left(\mathrm{Na}_{2} \mathrm{CO}_{3}\right)$ & 144 \\
\hline $2 \% \mathrm{CoO}_{\mathrm{x}} / \mathrm{MgO}\left(\mathrm{Na}_{2} \mathrm{CO}_{3}\right)$ & 151 \\
\hline used $2 \% \mathrm{CoO}_{\mathrm{x}} / \mathrm{MgO}$ & 60 \\
\hline regenerated $2 \% \mathrm{CoO}_{\mathrm{x}} / \mathrm{MgO}$ & 122 \\
\hline
\end{tabular}

result in pore enlargement, which leads to an increase of the specific surface area.
It is well known that a higher specific surface area means more active sites. More phenol and intermediates can be absorbed on the catalyst, which can accelerate the degradation rate of phenol and intermediates. More ozone can be converted to free radicals over the catalyst, further increasing the catalytic reaction rate. ${ }^{11}$ The catalysts were prepared by $\mathrm{NaOH}$ (strong alkaline) and $\mathrm{NH}_{3} \cdot \mathrm{H}_{2} \mathrm{O}$ (weak alkaline) as precipitators. The specific surface areas of $\mathrm{CoO}_{x} / \mathrm{MgO}$ prepared with $\mathrm{NaOH}$ and $\mathrm{NH}_{3} \cdot \mathrm{H}_{2} \mathrm{O}$ as precipitators are 45 and $67 \mathrm{~m}^{2} / \mathrm{g}$, respectively (shown in Figure S4 and Table 1), which were much lower than that of the one prepared by $\mathrm{Na}_{2} \mathrm{CO}_{3}$. It suggests that alkalinity has a great influence on the structures and properties of catalysts. The catalytic activities of catalysts prepared by different precipitators are also different, 

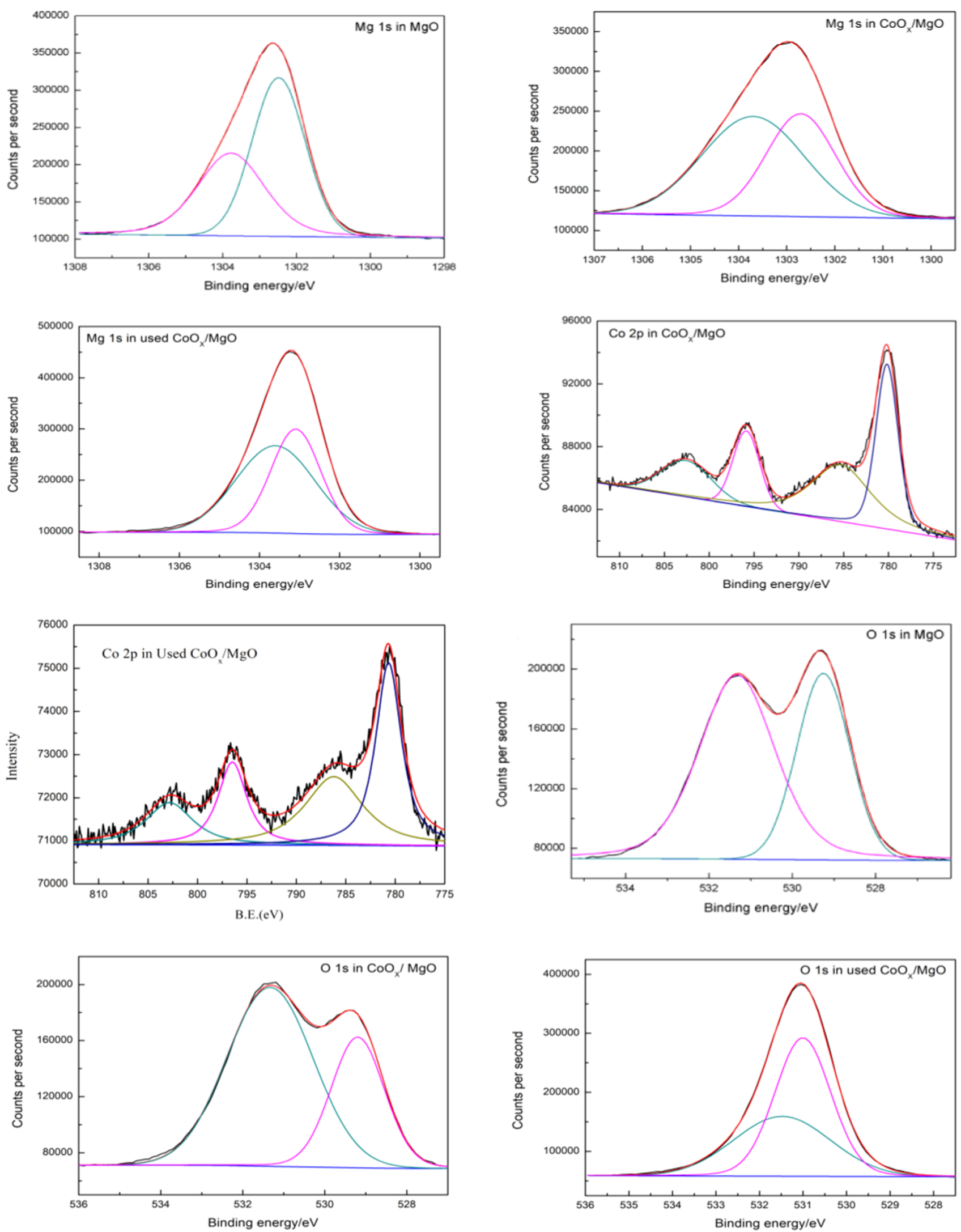

Figure 3. XPS spectra of Mg 1s, Co 2p, and O 1s.

which will be discussed in Section 2.2. There are some factors that affect the decrease of the surface area of used $\mathrm{CoO}_{\mathrm{x}} / \mathrm{MgO}$, such as conversion of $\mathrm{MgO}$, adsorption of other organics, and so on. The recovered catalysts were alternately washed with ethanol and water, then dried, and calcined; the surface area of regenerated catalysts was almost recovered.

2.1.4. Surface Chemical States of Catalysts. To further investigate the surface chemistry of catalysts, X-ray photo- 
electron spectroscopy (XPS) was performed to study the surface $\mathrm{Mg}, \mathrm{Co}$, and $\mathrm{O}$ species on $\mathrm{MgO}, 2 \% \mathrm{CoO}_{\mathrm{x}} / \mathrm{MgO}$, and used $2 \% \mathrm{CoO}_{\mathrm{x}} / \mathrm{MgO}$ (Figure 3). The binding energy (BE) values of 1303.6 and $1303.7 \mathrm{eV}$ can be attributed to $\mathrm{Mg}^{2+}$ in $\mathrm{Mg}(\mathrm{OH})_{2}$ and $\mathrm{Mg}$ salts, respectively. ${ }^{15,29}$ The peaks appearing at $1302.5,1302.7$, and $1303.1 \mathrm{eV}$ can correspond to $\mathrm{Mg}$ species in the three catalysts. As seen in Table $\mathrm{S} 1$ that after $\mathrm{CoO}_{\mathrm{x}}$ loading, the intensity of the $\mathrm{Mg}(\mathrm{OH})_{2}$ peak increased. It suggests that the addition of $\mathrm{CoO}_{\mathrm{x}}$ can increase the amount of $\mathrm{OH}^{-}$on the surface of catalysts, which is in good agreement with the results of Fourier transform infrared (FTIR) spectroscopy. The increase of $\mathrm{OH}^{-}$on the surface is beneficial for catalytic ozonation, ${ }^{26}$ which provides active sites for the decomposition of ozone to radicals. Peak's area of Mg species changed little after the reaction.

The Co $2 p$ profile was achieved with the assumption of four species. The peaks emerging at 802.6, 795.9, 796.3, 785.4, 786.1, 780.2, and $780.6 \mathrm{eV}$ can correspond to $\mathrm{Co}^{3+}$ (sat), $\mathrm{Co}^{2+}$, $\mathrm{Co}^{3+}, \mathrm{Co}^{2+}$ (sat), $\mathrm{Co}^{3+}$ (sat), $\mathrm{Co}^{2+}$, and $\mathrm{Co}^{3+}$, respectively. The results also show that Co was successfully loaded on $\mathrm{MgO}^{30}$ The binding energies of these Co species were all increased, and the area ratios of $\mathrm{Co}^{3+}$ and its satellite peak became larger. It suggests that some $\mathrm{Co}^{2+}$ has been oxidized to $\mathrm{Co}^{3+}$ during the reaction. To maintain an electrostatic charger balance on the catalyst surface, the transition occurring in different valence states of Co may activate the lattice oxygen and enhance the catalytic activity. ${ }^{11}$

In the case of $\mathrm{O}$ 1s spectra shown in Figure 3, the peaks at $529.2,529.3$, and $531.0 \mathrm{eV}$ belong to lattice oxygen species, and the peaks at 531.3, 531.3, and $531.5 \mathrm{eV}$ can be attributed to chemisorbed oxygen species, such as $\mathrm{O}^{2-}, \mathrm{O}_{2}{ }^{2-}$, and $\mathrm{O}^{-}{ }^{31} \mathrm{It}$ should be noted that the electrophilic chemisorbed oxygen species play a vital role in deep oxidation of organics. ${ }^{32}$ It can be seen from the spectrum of $\mathrm{O} 1 \mathrm{~s}$ in $\mathrm{MgO}$ and $\mathrm{CoO}_{\mathrm{x}} / \mathrm{MgO}$ and Table S3 that when Co was doped with $\mathrm{MgO}$, the ratio of adsorbed oxygen to lattice oxygen increased obviously, which was one of the main reasons for the improvement of catalytic activity. However, for the used $\mathrm{CoO}_{\mathrm{x}} / \mathrm{MgO}$, the ratio of lattice oxygen species to adsorbed oxygen is 1.40 to 1 ; this may be because the surface of adsorbed oxygen was converted to lattice oxygen in a saturated ozone atmosphere. The synergistic effect of uniform distribution of $\mathrm{Co}$ and $\mathrm{Mg}$ active sites in the nanocages and the optimum molar ratio of $\mathrm{Co} / \mathrm{Mg}$ also can cause this phenomenon, so $\mathrm{CoO}_{\mathrm{x}} / \mathrm{MgO}$ exhibits better catalytic performance than pure $\mathrm{MgO}$ catalysts.

2.1.5. Surface Alkalinity of Catalysts. The alkaline properties of $\mathrm{MgO}, 2 \% \mathrm{CoO}_{\mathrm{x}} / \mathrm{MgO}$, and used $2 \% \mathrm{CoO}_{\mathrm{x}} /$ $\mathrm{MgO}$ were analyzed by temperature-programmed desorption of $\mathrm{CO}_{2}\left(\mathrm{CO}_{2}\right.$-TPD), which are shown in Figure 4. The peaks shown at around $105{ }^{\circ} \mathrm{C}$ in $\mathrm{MgO}$ can correspond to the weak alkalescent site. The peaks at higher temperatures than $200{ }^{\circ} \mathrm{C}$ correspond to the strong alkalescent sites, such as oxygen in the $\mathrm{Mg}^{2+}$ and $\mathrm{O}^{2-}$ pairs and isolated $\mathrm{O}^{2-31}$ With the addition of $\mathrm{CoO}_{x}$, the $\mathrm{CO}_{2}$ desorption temperature of these two peaks increased obviously. This indicates that the addition of $\mathrm{CoO}_{\mathrm{x}}$ can improve the surface alkalinity of catalysts. The surface alkalinity of catalysts was further enhanced after the reaction. The reason was that some $\mathrm{MgO}$ was transformed to $\mathrm{Mg}(\mathrm{OH})_{2}$ due to the hydration reaction between $\mathrm{MgO}$ and $\mathrm{H}_{2} \mathrm{O}$. The number of strong alkalescent sites is much more than that of weak ones in these three catalysts, and the strong alkalescent sites can promote the active sites on the surface of the catalyst. $^{27}$

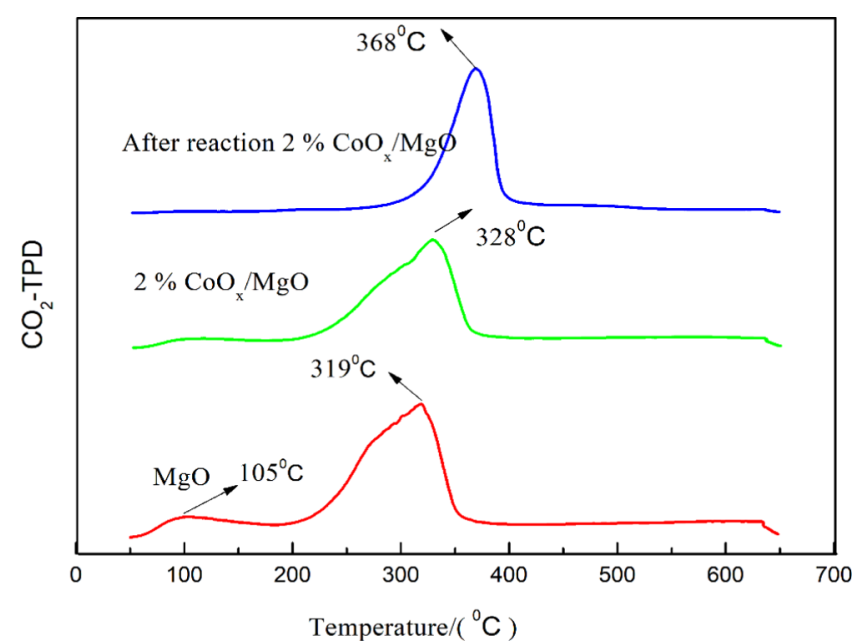

Figure 4. $\mathrm{CO}_{2}$-TPD profiles of $\mathrm{MgO}, 2 \% \mathrm{CoO}_{\mathrm{x}} / \mathrm{MgO}$, and used $2 \%$ $\mathrm{CoO}_{\mathrm{x}} / \mathrm{MgO}$.

FTIR has also been performed to detected $-\mathrm{OH}$ on these catalysts (Figure 5). Species of surface functional groups on

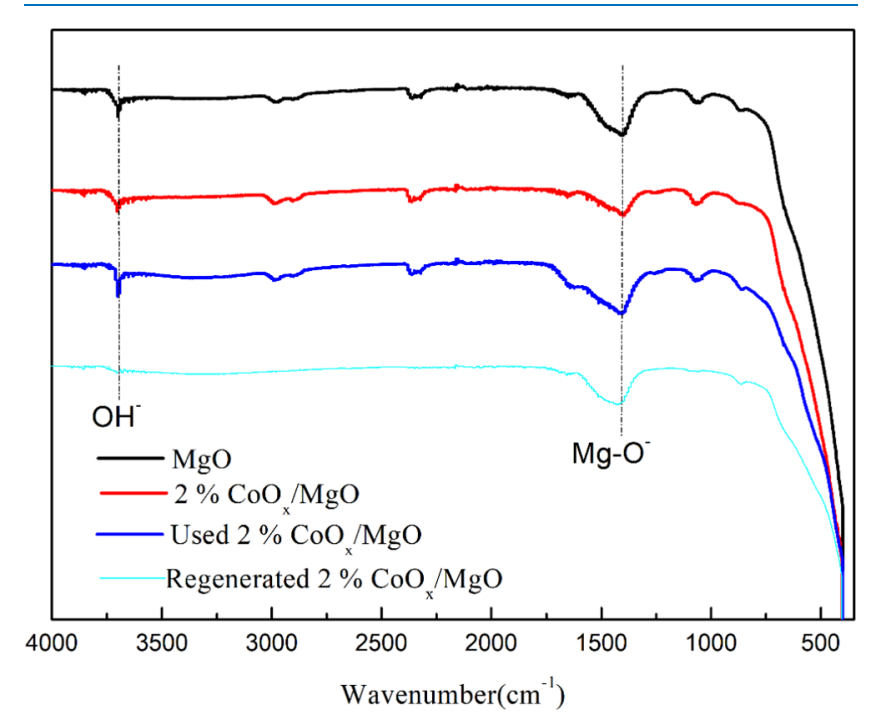

Figure 5. FTIR spectra of $\mathrm{MgO}, 2 \% \mathrm{CoO}_{\mathrm{x}} / \mathrm{MgO}$, and used and regenerated $2 \% \mathrm{CoO}_{\mathrm{x}} / \mathrm{MgO}$.

$\mathrm{CoO}_{\mathrm{x}} / \mathrm{MgO}$ have not changed much before and after the reaction except the strength. The vibrations at 1445 and 3700 $\mathrm{cm}^{-1}$ can correspond to the stretching vibrations of $\mathrm{Mg}-\mathrm{O}$ and $\mathrm{O}-\mathrm{H}$ vibrations in $\mathrm{Mg}(\mathrm{OH})_{2}$ or hydroxyl groups formed from water molecules absorbed on catalysts, respectively. ${ }^{25}$ The existence of hydroxyl groups on the surface of $\mathrm{MgO}$ can change the $\mathrm{pH}$ of the solution to about 11 , thereby promoting the generation of free radicals and improving the catalytic activity. $^{26-28}$

2.2. Catalytic Ozonation. 2.2.1. Catalytic Ozonation over Different Catalysts. Figure 6 shows that the removal rate of COD can reach 24.3, 37, 59.1, 76.2, and $79.8 \%$ without catalysts over $\mathrm{CoO}_{x}$, market $\mathrm{MgO}, \mathrm{MgO}$, and $2 \% \mathrm{CoO}_{x} / \mathrm{MgO}$ in $120 \mathrm{~min}$, respectively. It suggests that $2 \% \mathrm{CoO}_{\mathrm{x}} / \mathrm{MgO}$ and $\mathrm{MgO}$ showed much better activity than other catalysts. The addition of $\mathrm{CoO}_{\mathrm{x}}$ further enhanced the activity of $\mathrm{MgO}$. The removal rate of $\mathrm{COD}$ is relatively fast with $\mathrm{MgO}$ and $2 \%$ $\mathrm{CoO}_{\mathrm{x}} / \mathrm{MgO}$ as catalysts in the first $30 \mathrm{~min}$ due to high 


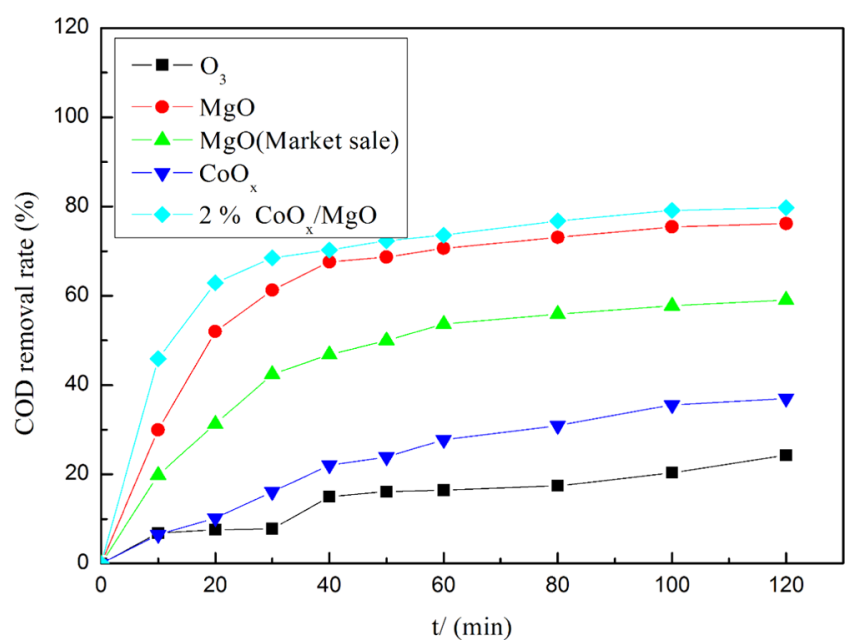

Figure 6. COD removal of phenol in ozonation and catalytic ozonation with time. Reaction conditions: temperature $=25{ }^{\circ} \mathrm{C}$; $[\mathrm{phenol}]_{0}=210 \mathrm{mg} / \mathrm{L} ;\left[\mathrm{O}_{3}\right] \mathrm{g}=43 \mathrm{mg} / \mathrm{L} ;$ gas flow rate $=1.5 \mathrm{~L} / \mathrm{min}$; solution $\mathrm{pH}=5.51$; catalyst loading $=500 \mathrm{mg} ; \mathrm{CoO}_{\mathrm{x}}$ loading amount $=2 \%$.

concentrations of organic substances at the beginning of reactions. The originally acidic solution becomes alkalescent after the addition of catalysts $(\mathrm{pH}$ is about 11) at the same time. Some research studies show that ozone is more soluble in alkalescent conditions and results in generation of more hydroxyl radicals for the degradation of phenol and its intermediates than in acidic or neutral conditions. However, if $\mathrm{NaOH}$ was added to tune the solution to alkalescent $(\mathrm{pH}$ 11 ) and as a catalyst, the COD removal rate was very low (about $25 \%$ in $2 \mathrm{~h}$ ). After $30 \mathrm{~min}$, the reaction rate was relatively slow. The reason may be that the increase of $\mathrm{OH}^{-}$ concentration led to the quenching reactions, which can hinder the further increase of ${ }^{\circ} \mathrm{OH}$ concentration. ${ }^{35}$ On the other hand, more $\mathrm{CO}_{2}$ was generated by the increase of solution $\mathrm{pH}$ from the decomposition of phenol and its intermediates. This generated $\mathrm{CO}_{2}$ can react with $\mathrm{OH}^{-}$to produce $\mathrm{CO}_{3}{ }^{2-}$ and $\mathrm{HCO}_{3}{ }^{-}$. ${ }^{\circ} \mathrm{OH}$ can also be consumed by $\mathrm{CO}_{3}{ }^{2-}$ and $\mathrm{HCO}_{3}{ }^{-}$, which can decrease the ${ }^{\circ} \mathrm{OH}$ concentration and then decrease the reaction rate. ${ }^{36}$ The decrease of phenol and its intermediates' concentration also led to a decrease of reaction rate. It also can be seen from Figure 5 that the COD removal rate over $\mathrm{CoO}_{\mathrm{x}} / \mathrm{MgO}$ is $3.6 \%$ higher than that over $\mathrm{MgO}$. The results have been confirmed by three parallel experiments to make sure it is not an error. XRD, TEM, XPS, and $\mathrm{CO}_{2}$-TPD proved that the surface morphology, surface activity, and surface alkalinity of the catalyst had been changed after $\mathrm{CoO}_{x}$ loading. The details of the reaction mechanism will be discussed in the following sections.

2.2.2. Synergistic Effect of $\mathrm{CoO}_{x} / \mathrm{MgO}$ and $\mathrm{O}_{3}$. The major role of catalytic ozonation rather than adsorption in the removal rate of COD was also confirmed. The content of COD that can be removed by adsorption was determined. Figure 7 shows that the COD removal rate was only $4.9 \%$ without $\mathrm{O}_{3}$ by $\mathrm{CoO}_{\mathrm{x}} / \mathrm{MgO}$ alone. This indicates that the amount of $\mathrm{COD}$ removed by adsorption is very small. The COD removal rate was only $25 \%$ in the system with $\mathrm{O}_{3}$ but without catalysts in $120 \mathrm{~min}$. This demonstrates that catalysts are essential for the efficient removal of COD. Although the specific surface area, pore size, pore volume, and surface morphology of $\mathrm{CoO}_{x} /$ $\mathrm{MgO}$ catalyst changed after modification, the changes of these

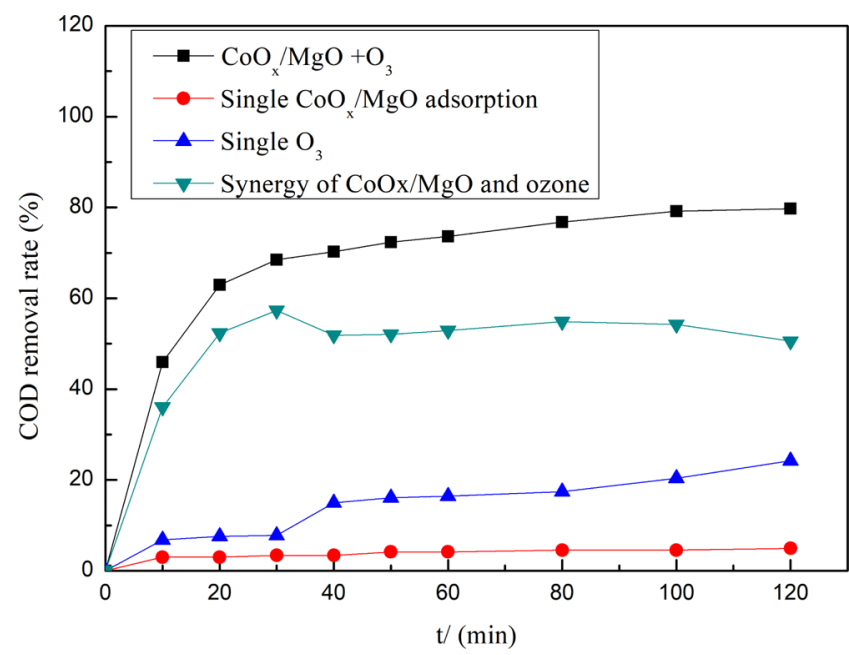

Figure 7. Effect of $\mathrm{CoO}_{\mathrm{x}} / \mathrm{MgO}$ adsorption alone on the $\mathrm{COD}$ removal rate.

physical parameters did not have a favorable effect on the removal rate of $\mathrm{COD}$ in the adsorption process. To demonstrate the role of the catalyst in catalytic ozonation, the synergistic effect of $\mathrm{CoO}_{\mathrm{x}} / \mathrm{MgO}$ and ozone is calculated. ${ }^{3-35}$ It can be seen from Figure 7 that the synergistic effect can reach $57.3 \%$ after $30 \mathrm{~min}$. This verifies the high activity of $\mathrm{CoO}_{\mathrm{x}} / \mathrm{MgO}$ for the degradation of phenol by the ozone reaction.

2.2.3. Effect of Catalysts' Calcination Temperature and Molar Ratio of Co to $\mathrm{Mg}$. The calcination temperature of catalysts and the molar ratio of $\mathrm{Co}$ to $\mathrm{Mg}$ have been optimized to get the best catalytic results (Figures S6 and S7). As can be seen in Figure S6, with an increase of calcination temperature, the removal rate of COD first increased from 75.1 to $79.8 \%$ $\left(500{ }^{\circ} \mathrm{C}\right)$ and then decreased to $75.8 \%$ with the calcination temperature increased from 400 to $600{ }^{\circ} \mathrm{C}$. The reason may be that the precursor cannot be completely decomposed at low calcination temperatures, while catalysts will be sintered at too high temperatures. Too high or too low temperatures all lead to fewer active sites. The lattice defects produced on the catalyst prepared at $500{ }^{\circ} \mathrm{C}$ can increase the charge density of $\mathrm{O}$ atoms and increase the number of active sites. ${ }^{36}$ About $90 \%$ phenol has been removed in $50 \mathrm{~min}$ and $100 \%$ phenol has been removed in $2 \mathrm{~h}$ (Figure S8).

The removal rate of COD increased from 76.9 to $79.8 \%$ (50:1) and then decreased with the Co molar ratio increasing from 10:1 to 110:1 (Figure S7). The $\mathrm{pH}$ of the reaction mixture increased from 9.5 to $11.3(50: 1)$ and then decreased with the Co molar ratio increasing from 10:1 to 110:1. This indicated that too much Co may cause a decrease of catalyst alkalinity, and the active sites were reduced. However, too little Co will reduce the oxygen defects on the catalyst and lead to a decrease of active sites, and the catalytic performance is reduced. Indeed, the appropriate molar ratio of $\mathrm{Mg}$ to Co was 50:1.

2.2.4. Effect of Phenol Concentration. The COD removal rates over $\mathrm{CoO}_{\mathrm{x}} / \mathrm{MgO}$ for different initial concentrations of the phenol solution have also been tested. With the increase of initial concentration of phenol from 50 to $400 \mathrm{mg} / \mathrm{L}$, the removal rate of COD decreased from 96.1 to $66.1 \%$ (Figure 8 ). With the increase of initial concentration of phenol, the treatment capacity increased, which resulted in the decrease of 

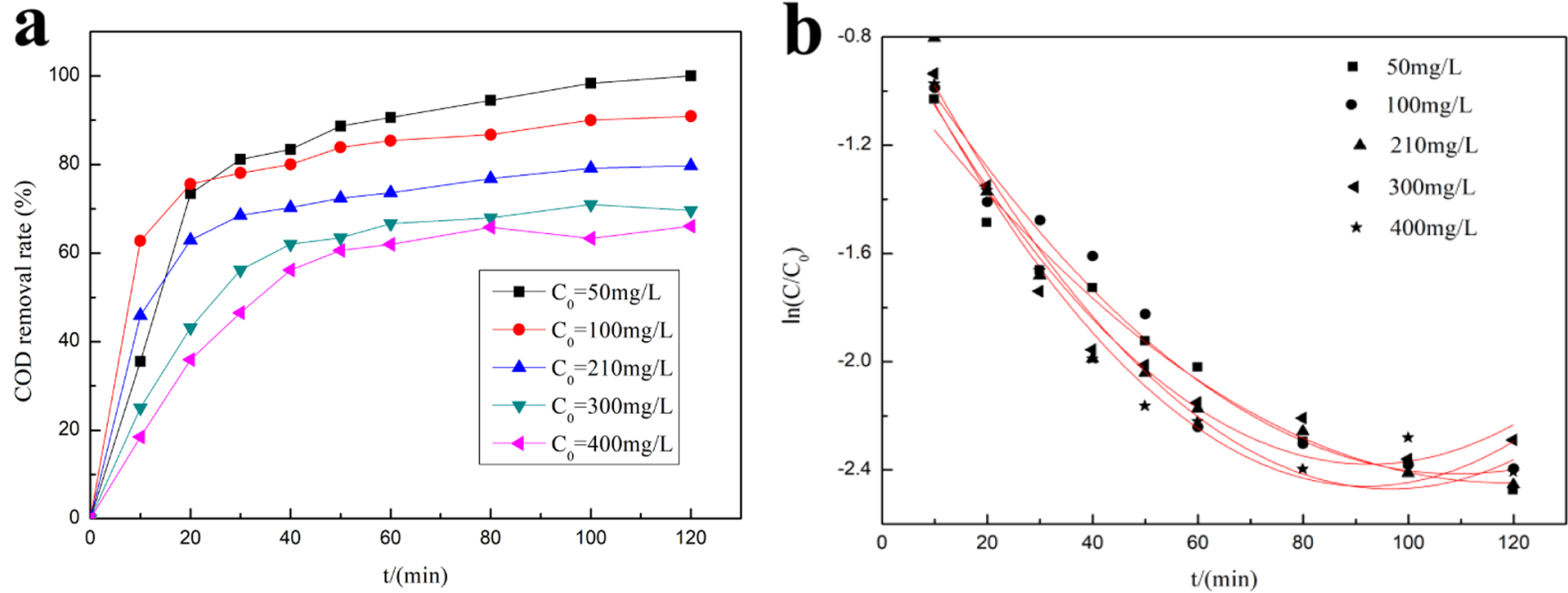

Figure 8. (a) Effect of different initial concentrations of phenol on the COD removal rate and (b) pseudo-second-order dynamical models for different initial concentrations of phenol.

Table 2. Dynamical Models for Different Initial Concentrations of Phenol

$\begin{array}{rl}\text { phenol concentration }(\mathrm{mg} / \mathrm{L}) & \text { fitting equation } \\ 50 & y=0.000214141 x^{2}-0.05089 x+0.16722 \\ 100 & y=0.00014222 x^{2}-0.03107 x-0.71743 \\ 210 & y=0.000136506 x^{2}-0.02640 x-0.3322 \\ 300 & y=0.000129683 x^{2}-0.02404 x-0.13701 \\ 400 & y=0.000128683 x^{2}-0.02368 x-0.02422\end{array}$

$\begin{array}{ccc} & R^{2} & K_{1} / \mathrm{min}^{-1} \\ 0.9709 & 2.14 \times 10^{-4} \\ 0.9533 & 1.42 \times 10^{-4} \\ 0.9392 & 1.37 \times 10^{-4} \\ 0.9515 & 1.30 \times 10^{-4} \\ 1 & 0.9588 & 1.29 \times 10^{-4}\end{array}$

COD removal rate. The high initial concentration of phenol will produce more intermediates, and the complex substance species in the solution will result in the decrease of COD removal efficiency, so this catalyst is suitable to treat phenol wastewater with concentrations lower than $210 \mathrm{mg} / \mathrm{L}$, which is more common in the industrial situation.

To further analyze the catalytic ozonation process, the pseudo-second-order dynamical models were fitted. It can be seen from Table 2, the correlation coefficients were 0.9709, $0.9533,0.9612,0.9515$, and 0.9588 corresponding to the initial phenol concentrations of 50,100,210,300, and $400 \mathrm{mg} / \mathrm{L}$, respectively. It indicated that the phenol degraded by catalytic ozonation over $\mathrm{CoO}_{\mathrm{x}} / \mathrm{MgO}$ tallied with pseudo-second-order kinetic laws. The reaction rate $\mathrm{K}_{1}$ decreased with the initial concentration increasing due to the decrease of the amount of phenol treated per unit and the increase of intermediate products accumulate amount at the same time, so the initial concentration of phenol is negatively correlated with the reaction rate constant.

2.2.5. Effect of $\mathrm{pH}$. The effect of $\mathrm{pH}$ of the initial phenol solution has little influence on catalytic performance. When the $\mathrm{pH}$ is $2.48,4.45,6.30,8.34$, and 10.23 , the COD removal rate can reach 79.0, 79.7, 79.8, 79.8, and 82.1\% (Figure S8), respectively. $\mathrm{CoO}_{\mathrm{x}} / \mathrm{MgO}$ is strongly alkaline; although the initial $\mathrm{pH}$ was adjusted from acid to alkaline, once added the catalyst, the solution $\mathrm{pH}$ is about 10 . Under the alkaline conditions, the amount of ozone dissolved in the solution increased, and more hydroxyl radicals were generated to enhance the COD removal rate.

2.3. Reaction Mechanism. 2.3.1. Effect of Hydroxyl Radicals and Surface Lewis Acid Sites. Hydroxyl radical is the strongest oxidable species in this system and plays a key role in the treatment of organic wastewater by catalytic ozonation.
TBA (Tianjin Damao Chemical Reagent Factory, China) was added to the reaction system to verify the role of hydroxyl radical in the reactions. It is well known that TBA can be used as a radical scavenger to suppress the generated hydroxyl radicals, which can react with ${ }^{\circ} \mathrm{OH}$ at a high reaction rate constant of $6 \times 10^{8} \mathrm{M}^{-1} \cdot \mathrm{s}^{-1}$, while it reacts with $\mathrm{O}_{3}$ only at a reaction rate constant of $3 \times 10^{-3} \mathrm{M}^{-1} \cdot \mathrm{s}^{-1} \cdot{ }^{3737}$ As can be seen from Figure 9, the COD removal rate was only about $1 \%$ with the addition of TBA in $2 \mathrm{~h}$, while the removal rate of COD can

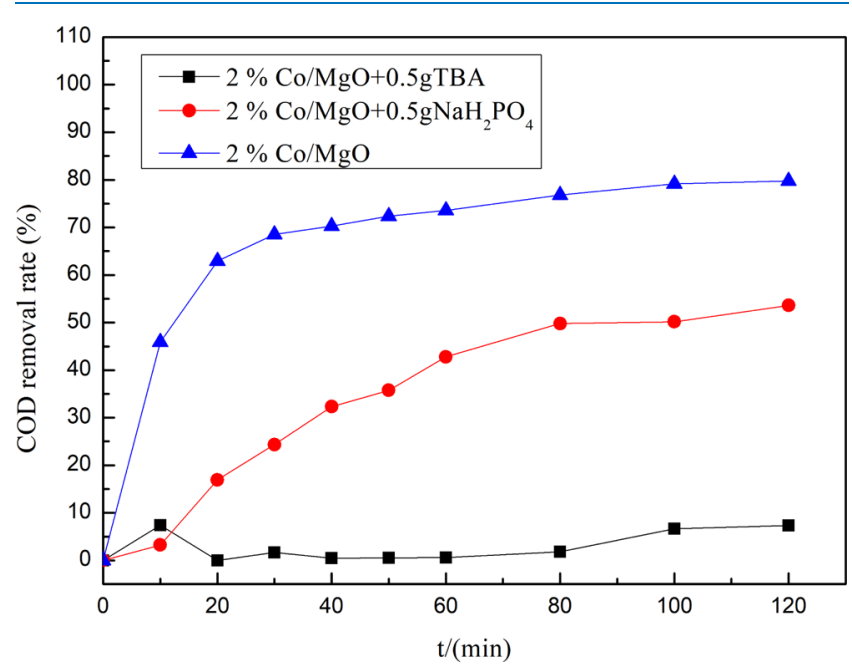

Figure 9. COD removal rate of phenol in catalytic ozonation in the presence of TBA or $\mathrm{Na}_{2} \mathrm{HPO}_{4}$ at different reaction times. Reaction conditions: temperature $=25{ }^{\circ} \mathrm{C}$; $[\mathrm{phenol}]_{0}=210 \mathrm{mg} / \mathrm{L} ;\left[\mathrm{O}_{3}\right] \mathrm{g}=43$ $\mathrm{mg} / \mathrm{L}$; gas flow rate $=1.5 \mathrm{~L} / \mathrm{min}$; solution $\mathrm{pH}=5.51$; catalyst loading $=500 \mathrm{mg} ; \mathrm{CoO}_{\mathrm{x}}$ loading amount $=2 \%$. 

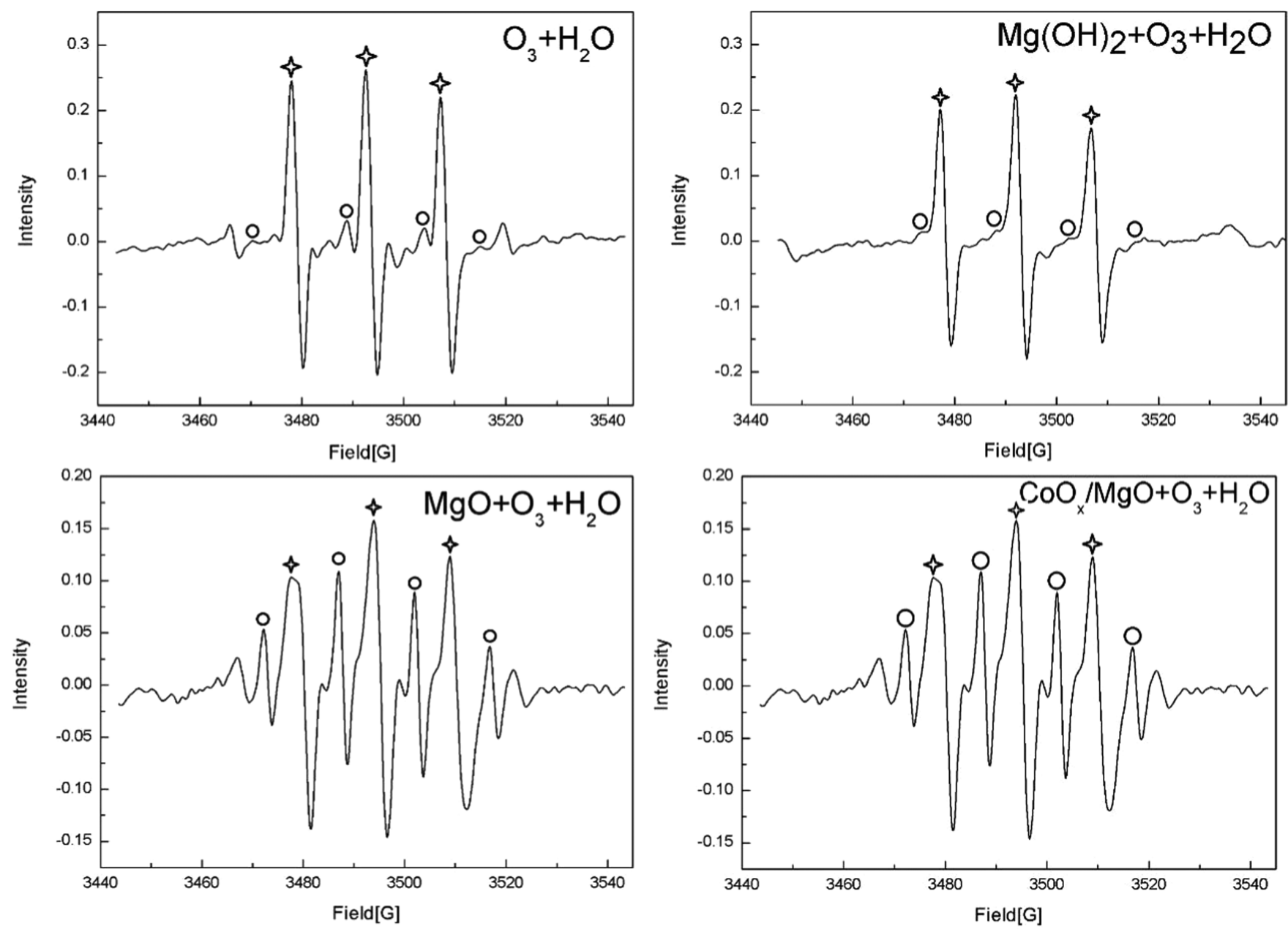

Figure 10. EPR spectra of radicals in the reaction system with or without catalysts $\left(O, \mathrm{DMPO}{ }^{\bullet} \mathrm{OH} ; \diamond, \mathrm{DMPO}-\mathrm{O}_{2}\right)$.

reach $79.8 \%$ in the experiment without TBA in $2 \mathrm{~h}$. Therefore, the hydroxyl radical plays a dominant role in the experiment. These results also indicated that $2 \% \mathrm{CoO}_{\mathrm{x}} / \mathrm{MgO}$ can effectively promote the conversion of ozone molecules to hydroxyl radicals, which results in nonselective reactions with intermediates and leads to a high COD removal rate.

According to the previous report, Lewis acidic sites may act as active sites for the generation of hydroxyl radicals from ozone, so $\mathrm{NaH}_{2} \mathrm{PO}_{4}$ (Tianjin Damao Chemical Reagent Factory, China) was added to the reaction system to verify the effect of Lewis acid position on the catalyst surface. ${ }^{38}$ $\mathrm{NaH}_{2} \mathrm{PO}_{4}$ is a strong Lewis base, which can easily cover the Lewis acid site on the surface of the catalyst. ${ }^{38,39}$ It can be seen from Figure 8 that the COD removal rate was $53.6 \%$ after the addition of $\mathrm{NaH}_{2} \mathrm{PO}_{4}$, which was much lower than the one without $\mathrm{NaH}_{2} \mathrm{PO}_{4}$. It indicates that Lewis acidic sites act as parts of active sites for this process, while other kinds of active sites also exist, which will be discussed in the next section. It can be seen from Figure S5 that the regenerated catalyst from the system which was added some $\mathrm{NaH}_{2} \mathrm{PO}_{4}$ has only a few petal-like changes on the surface of the catalyst, and the shape is almost unchanged compared with the catalyst before the reaction. It demonstrates that it suppressed the hydration of $\mathrm{MgO}$ to $\mathrm{Mg}(\mathrm{OH})_{2}$, which is important for this process. $\mathrm{NaH}_{2} \mathrm{PO}_{4}$ also leads to the passivation of the catalyst, inhibits the electron transfer on the surface of $\mathrm{CoO}_{\mathrm{x}} / \mathrm{MgO}$, and reduces the number of active sites, which leads to the decrease of catalytic activity. ${ }^{38}$ The results show the change of Lewis acid position on the catalyst surface. The surface morphology of the catalyst is closely related to the catalytic activity.

2.3.2. Mechanism of Catalytic Ozonation over $\mathrm{CoO}_{x} /$ $\mathrm{MgO}$. To detect the radicals generated from $\mathrm{O}_{3}$ degradation, in situ EPR has been performed. In situ EPR experiments have been carried out by the following steps. First, $50 \mathrm{~mL}$ of phenol solution of $210 \mathrm{mg} / \mathrm{L}$ and catalysts (or without catalysts) were added into a three-necked flask. Second, $\mathrm{O}_{3}$-containing air flow was blown into the solution. The mixture was stirred for 10 min, and then, $0.1 \mathrm{~g}$ of 5,5-dimethyl-1-pyrroline $\mathrm{N}$-oxide (DMPO) was added to the mixture and reacted for $5 \mathrm{~min}$. Solution samples were taken by injectors and characterized by EPR. As can be seen in Figure 10, three main peaks emerged in these four spectra marked by a four-pointed star, which can correspond to singlet oxygen combined by DMPO. The intensity of these peaks remained constant after the addition of $\mathrm{Mg}(\mathrm{OH})_{2}$, while it decreased obviously after the addition of $\mathrm{MgO}$ and $\mathrm{CoO}_{\mathrm{x}} / \mathrm{MgO}$. Four peaks with the relative intensity ratio of $1: 2: 2: 1$, which were marked by cycles, can correspond to ${ }^{\circ} \mathrm{OH}$ combined with DMPO (DMPO-OH). These four peaks appeared in all of these four systems, which indicates the generation of ${ }^{\bullet} \mathrm{OH}$ in these systems. ${ }^{\bullet} \mathrm{OH}$ is the main oxidant for the degradation of phenol, so some phenol molecules can be decomposed by $\mathrm{O}_{3}$ even without any catalysts. After the addition of $\mathrm{MgO}$ and $\mathrm{CoO}_{\mathrm{x}} / \mathrm{MgO}$, the intensity of DMPO-OH peaks increased by about 4.2 and 4.3 times, respectively. This 
demonstrates that the addition of $\mathrm{MgO}$ and $\mathrm{CoO}_{\mathrm{x}} / \mathrm{MgO}$ can accelerate the generation of ${ }^{\bullet} \mathrm{OH}$, which led to the great increase of the COD removal rate and ratio. The addition of $\mathrm{CoO}_{\mathrm{x}}$ in $\mathrm{MgO}$ can enhance the catalytic activity of $\mathrm{MgO}$. The addition of $\mathrm{Mg}(\mathrm{OH})_{2}$ seemed to have a little influence on the generation of ${ }^{\circ} \mathrm{OH}$ because there was no obvious increase of DMPO-OH peaks' intensity, and the COD removal rate and ratio were also much lower than the ones with the addition of $\mathrm{MgO}$ and $\mathrm{CoO}_{\mathrm{x}} / \mathrm{MgO}$. This indicates that the catalytic activity of $\mathrm{Mg}(\mathrm{OH})_{2}$ is much weaker than that of $\mathrm{MgO}$ and $\mathrm{CoO}_{\mathrm{x}} /$ $\mathrm{MgO}$. The COD removal ratio of systems with $\mathrm{Mg}(\mathrm{OH})_{2}$ (38.2\% in $120 \mathrm{~min}$ ) is higher than the one without any catalysts (22.5\% in 120 min, Figure S9). This demonstrates that $\mathrm{Mg}(\mathrm{OH})_{2}$ may not accelerate phenol degradation by the way of acceleration of ${ }^{\bullet} \mathrm{OH}$ generation. It may increase the solubility of $\mathrm{O}_{3}$ due to its strong alkalinity.

$\mathrm{MgO}$ hydration may play the main role in the degradation of phenol because when the Lewis acidic sites have been blocked, there was still 53.6\% COD removal ratio, while when $\mathrm{Mg}(\mathrm{OH})_{2}$ was used as catalysts, only $38.2 \%$ COD removal rate was obtained in $120 \mathrm{~min}$ (Figure S9). It was also proved by the results of SEM and XRD that the hydration of MgO did occur during the experiment. It can be seen from the SEM images shown in Figure S2 that the surface morphology of $\mathrm{CoO}_{\mathrm{x}} / \mathrm{MgO}$ changed little after the addition of phosphate. The COD removal rate decreased significantly after the addition of phosphate (Figure 8). This suggests that the hydration of $\mathrm{MgO}$ has a certain effect on the catalytic oxidation reaction.

Combined with the hydration mechanism of $\mathrm{MgO}$, the possible degradation mechanism of phenol by $\mathrm{CoO}_{x} / \mathrm{MgO}$ was summarized. $\mathrm{MgO}$ reacts with water to form surface hydroxyl and free hydrogen and oxygen radicals. $\mathrm{MgO}-\mathrm{OH}^{+}$reacts with ozone molecules to form oxygen free radicals on the surface of $\mathrm{MgO}$. The ozone and water molecules are adsorbed on the surface of $\mathrm{MgOO}^{-}$and interact to form surface hydroxyl radicals and free hydroxyl radicals. $\mathrm{MgO}$ hydrates slowly in an environment where $\mathrm{CO}_{2}$ is constantly produced. Finally, $\mathrm{MgOO}^{\bullet}$ and ${ }^{\bullet} \mathrm{OH}$ react with phenol to form $\mathrm{CO}_{2}, \mathrm{H}_{2} \mathrm{O}$, and intermediates. Intermediates further react with $\mathrm{MgOO}^{\bullet}$ and - $\mathrm{OH}$ to generate $\mathrm{CO}_{2}$ and $\mathrm{H}_{2} \mathrm{O}$. ${ }^{13}$

2.4. Stability of Catalysts. The stability of a catalyst is an important factor for its application. A series of experiments were carried out to explore the stability of the catalyst. It can be seen from Figure 11 that the removal rate of COD is about $79 \%$ after each cycle $(120 \mathrm{~min})$. The result indicates that prepared catalysts have good reusability for the catalytic ozonation reaction. The reason for the long catalytic life is the regeneration of oxygen vacancies on the catalyst surface and the increase of surface hydroxyl groups during calcination.

\subsection{Removal of COD from Wastewater with Different} Contaminants. The universality of a catalyst is also very important for its applications. Salicylic acid, ciprofloxacin, and norfloxacin solutions (initial concentration is $210 \mathrm{mg} / \mathrm{L}$ ) were used for the catalytic ozonation over $\mathrm{CoO}_{\mathrm{x}} / \mathrm{MgO}$ to test the universality of the catalyst under the same conditions as other experiments. It can be seen from Figure 12 that the COD removal rate can reach 97.6, 95.6, and $75.2 \%$ for the ciprofloxacin solution, norfloxacin solution, and salicylic acid solution, respectively. These results show that $\mathrm{CoO}_{\mathrm{x}} / \mathrm{MgO}$ also has a significant removal effect on other pollutants.

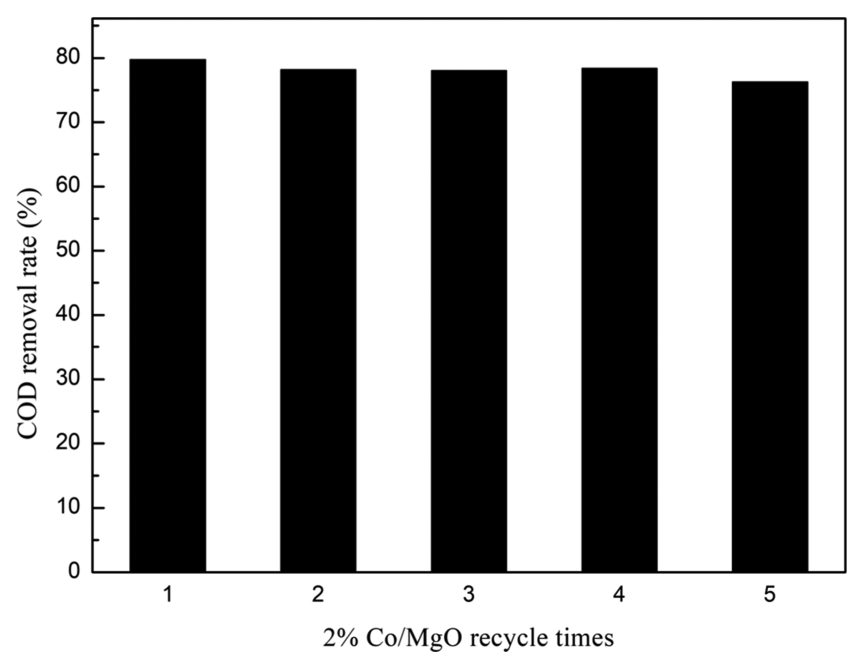

Figure 11. Stability of prepared $2 \% \mathrm{CoO}_{\mathrm{x}} / \mathrm{MgO}$ for catalytic ozonation of phenol.

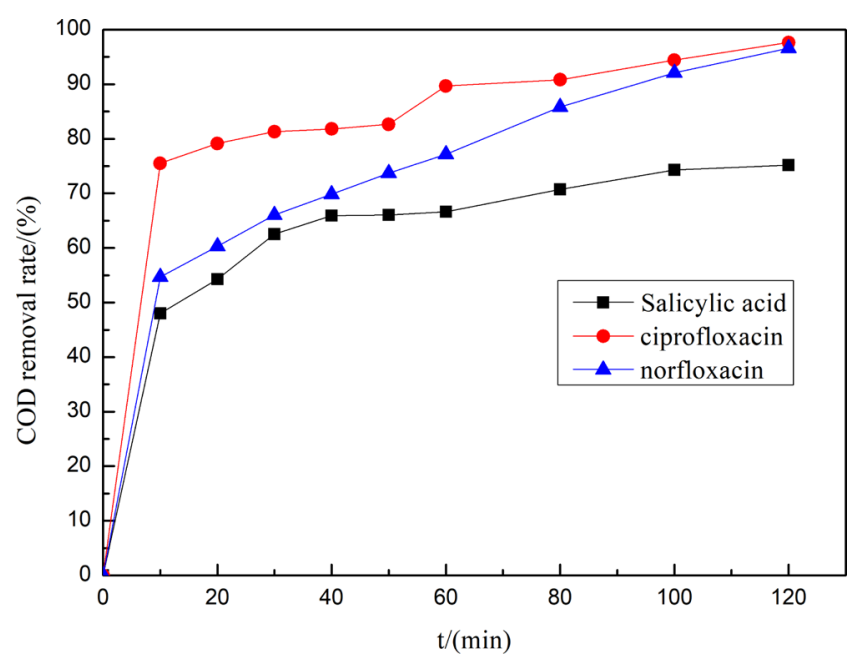

Figure 12. Removal rate of COD in different substrates treated by catalyst catalytic ozonation varied with time.

\section{CONCLUSIONS}

$\mathrm{CoO}_{\mathrm{x}} / \mathrm{MgO}$ was successfully prepared by coprecipitation, and it showed good activity in catalytic ozonation. The COD removal rate can reach $79.8 \%$ for phenol wastewater with initial concentrations of catalysts of $210 \mathrm{mg} / \mathrm{L}$ and $1.67 \mathrm{~g} / \mathrm{L}$. The various characterizations showed that high catalytic activity was due to the high specific surface area $\left(151.3 \mathrm{~m}^{2} / \mathrm{g}\right)$ and strong alkalinity of $\mathrm{CoO}_{\mathrm{x}} / \mathrm{MgO}$. The addition of $\mathrm{CoO}_{\mathrm{x}}$ in $\mathrm{MgO}$ can increase the ability of catalysts for conversion of $\mathrm{O}_{3}$ to free radicals, which degrades phenol more effectively. At the same time, hydration of $\mathrm{MgO}$ in the process can improve the ratio of COD. The experimental results showed that $\mathrm{CoO}_{\mathrm{x}} / \mathrm{MgO}$ also had high COD removal rates for norfloxacin, ciprofloxacin, and salicylic acid at the same initial concentration. Moreover, the prepared catalyst could be recycled five times without reducing its activity. This work provided a method for the subsequent design of catalysts with higher catalytic performance. It also provided an effective catalyst for phenol removal in wastewater.

\section{MATERIALS AND METHODS}

4.1. Preparation and Characterization of Catalysts. $\mathrm{CoO}_{\mathrm{x}} / \mathrm{MgO}$ was prepared by a coprecipitation method. First, 
$\mathrm{Mg}\left(\mathrm{NO}_{3}\right)_{2} \cdot 6 \mathrm{H}_{2} \mathrm{O}$ (23.59 g, AR, Tianjin Yongda Chemical Reagent Co., China) and $9.75 \mathrm{~g}$ of $\mathrm{Na}_{2} \mathrm{CO}_{3}$ (AR, Tianjin Yongda Chemical Reagent Co., China) were dissolved in 100 $\mathrm{mL}$ of deionized water. Second, $0.9769 \mathrm{~g} / \mathrm{L} \mathrm{Co}\left(\mathrm{NO}_{3}\right)_{2}(\mathrm{AR}$, Tianjin Yongda Chemical Reagent Co., China) solution was poured into the $\mathrm{Mg}\left(\mathrm{NO}_{3}\right)_{2}$ solution and stirred with a magnet in a beaker at room temperature for $15 \mathrm{~min}$; then, the $\mathrm{Na}_{2} \mathrm{CO}_{3}$ solution was quickly poured into the mixed solution of $\mathrm{Co}\left(\mathrm{NO}_{3}\right)_{2}$ and $\mathrm{Mg}\left(\mathrm{NO}_{3}\right)_{2}$ and stirred for $45 \mathrm{~min}$. The obtained suspension was aged for $4 \mathrm{~h} . \mathrm{Mg}^{2+}$ and $\mathrm{Co}^{2+}$ combined with $\mathrm{CO}_{3}{ }^{2-}$ form precipitation. The ratio of $\mathrm{Mg}^{2+}$ to $\mathrm{Co}^{2+}$, the combining rate of $\mathrm{Mg}^{2+}$ or $\mathrm{Co}^{2+}$ with $\mathrm{CO}_{3}{ }^{2-}$, and the numbers of $\mathrm{Mg}^{2+}$ or $\mathrm{Co}^{2+}$ coordination complexes are different; these factors may cause the catalysts to form a microrod structure. The suspension was filtered and washed with deionized water three times. The solid was dried at $90{ }^{\circ} \mathrm{C}$ for $6 \mathrm{~h}$, calcined in a muffle furnace at $500{ }^{\circ} \mathrm{C}$ (heating rate is 5 ${ }^{\circ} \mathrm{C} / \mathrm{min}$ ) for $4 \mathrm{~h}$, and naturally cooled down to room temperature. The catalysts were prepared. $\mathrm{CoO}_{\mathrm{x}} / \mathrm{MgO}$ was also prepared by different precipitants, $\mathrm{NaOH}$ and $\mathrm{NH}_{3} \cdot \mathrm{H}_{2} \mathrm{O}$, by the same process.

The crystallinity and crystal species of catalyst were analyzed by a D/MAX-2500 X-ray diffractometer (XRD) (Japan, Cu K $\alpha$ radiation, $60 \mathrm{kV}, 300 \mathrm{~mA}$ ). Catalyst morphologies were observed by an S-4800-I scanning electron microscopy (SEM) unit with $3 \mathrm{kV}$ voltage and $10 \mathrm{~mA}$ beam current. Transmission electron microscopy (TEM) was utilized to observe the internal structure of the catalyst using a lanthanum hexaboride filament as an electron emission source (Japan, JEOL, JEM-2100, 80-200 kV). The specific surface area and pore size distribution of the catalyst were analyzed by Brunauer-Emmett-Teller (BET) and Barret-Joyner-Halenda (BJH) methods on a Quantachrome NOVA2000 analyzer, respectively. Fourier transform infrared (FTIR) spectra were recorded by a Nicolet iS5, Thermal Fisher infrared spectrometer. The chemical states of the catalyst were determined by X-ray photoelectron spectroscopy (XPS) with a Kratos Axis Ultra DLD spectrometer and monochromated Al $\mathrm{K} \alpha$ radiation. The surface alkalinity of the catalyst was measured by temperature-programmed desorption of $\mathrm{CO}_{2}$ $\left(\mathrm{CO}_{2}\right.$-TPD) on an AutoChemIIChemisorption Analyzer (Micromeritics). EPR was performed on a Bruker EMXplus9.5/12 electronic paramagnetic resonance (EPR) spectrometer with the following settings: resonance frequency of $9.85 \mathrm{GHz}$, microwave power of $10.02 \mathrm{~mW}$, modulation frequency of 100 $\mathrm{kHz}$, modulation amplitude of $2.0 \mathrm{G}$, sweep width of $1000 \mathrm{G}$, time constant of $0 \mathrm{~ms}$, sweep time of $40.96 \mathrm{~s}$, and receiver gain of $2.0 \times 10^{4}$.

4.2. Catalytic Ozonation. Wastewater treatment by catalytic ozonation is a semi-intermittent process. The experiment was carried out in a three-necked round-bottom flask at $25{ }^{\circ} \mathrm{C}$ and atmosphere pressure. Ozone is produced by an ozone generator (MTS-CFG-50A, Qingdao Meites, mixed gas flow is $50 \mathrm{~g} / \mathrm{h}$ ). The concentration of ozone in the gas phase was measured by the iodine method according to the CJ/T3028.2-1994 standard, which was about $43 \mathrm{mg} / \mathrm{L}$. The flow rate of mixed gas was $1.5 \mathrm{~L} / \mathrm{min}$ (Figure S1). The excess ozone was also measured by KI (Tianjin Yongda Chemical Reagent Co., China.) solution prior. ${ }^{19}$

Phenol solution $(300 \mathrm{~mL})$ with a concentration of $210 \mathrm{mg} /$ $\mathrm{L}$ (in which COD was $520 \mathrm{mg} / \mathrm{L}$ ) was added to the reactor. $\mathrm{CoO}_{\mathrm{x}} / \mathrm{MgO}(0.5 \mathrm{~g})$ was added into the reactor. Then, $\mathrm{O}_{3}$ was inlet into the suspension with magnetic stirring. Samples of water were taken every $10 \mathrm{~min}$ and filtered with a $0.22 \mu \mathrm{m}$ filter membrane; chromic acid was added immediately for digestion and analyzed immediately. After the experiments, the catalyst was filtered, washed alternately with water and anhydrous ethanol (Tianjin Yongda Chemical Reagent Co., China.), and dried. The catalyst was roasted at $500{ }^{\circ} \mathrm{C}$ for $4 \mathrm{~h}$ for recycling.

4.3. COD Analytical Method. Chemical oxygen demand (COD) is an index to test the mineralization rate of organic compounds in water. Therefore, digestion and determination of samples were carried out according to the standard method by COD digestion instrument and a COD analyzer (Leici COD-571) $\left(\mathrm{K}_{2} \mathrm{Cr}_{2} \mathrm{O}_{7}, \mathrm{Ag}_{2} \mathrm{SO}_{4}\right.$, Tianjin Damao Chemical Reagent Factory, China). ${ }^{20}$ The samples were taken at different times and filtered with $0.22 \mu \mathrm{m}$ filter membrane after the beginning of the experiment; then, $2 \mathrm{~mL}$ of samples and $3 \mathrm{~mL}$ of chromic acid solutions were added to the sample tube immediately. The mixture was put into the digestion instrument for digestion. At the end of digestion, the digestion tube was removed and cooled to room temperature. The COD-571 tester was preheated for $30 \mathrm{~min}$. After calibration, the digested sample was carefully poured into the colorimetric dish and put into the instrument. After the display is stable, the COD concentration of the current sample was obtained.

The degree of phenol mineralization in the selected process was measured based on the initial $\operatorname{COD}\left(\mathrm{COD}_{0}\right)$ and the $\mathrm{COD}$ of the solution after the reaction $\left(\mathrm{COD}_{\mathrm{t}}\right)$

$$
\text { COD removal rate }(\%)=\frac{\mathrm{COD}_{0}-\mathrm{COD}_{t}}{\mathrm{COD}_{0}} \times 100
$$

\section{ASSOCIATED CONTENT}

\section{Supporting Information}

The Supporting Information is available free of charge at https://pubs.acs.org/doi/10.1021/acsomega.1c03497.

(1) Ozone solubility; (2) catalyst characterization: XRD details of $\mathrm{CoO}_{\mathrm{x}} / \mathrm{MgO}, \mathrm{N}_{2}$ physical adsorption and desorption isotherms of $\mathrm{MgO}, 2 \% \mathrm{CoO}_{\mathrm{x}} / \mathrm{MgO}$, and used $2 \% \mathrm{CoO}_{\mathrm{x}} / \mathrm{MgO}$ composites; $\mathrm{N}_{2}$ physical adsorption and desorption isotherms of $\mathrm{MgO}\left(\mathrm{NH}_{3} \mathrm{HO}\right)$ and $\mathrm{MgO}(\mathrm{NaOH}) ; \mathrm{SEM}$ image of used $2 \% \mathrm{CoO}_{\mathrm{x}} / \mathrm{MgO}$ (added $\mathrm{Na}_{2} \mathrm{HPO}_{4}$ ); XPS data of $\mathrm{Mg}$, Co, and $\mathrm{O}$ in different catalysts; and FTIR spectra of $\mathrm{MgO}, 2 \% \mathrm{CoO}_{\mathrm{x}} /$ $\mathrm{MgO}$, and used and regenerated $2 \% \mathrm{CoO}_{\mathrm{x}} / \mathrm{MgO}$; (3) catalytic ozonation: effect of $\mathrm{CoO}_{\mathrm{x}} / \mathrm{MgO}$ adsorption alone on the COD removal rate; effect of different calcination temperatures on the COD removal rate; effect of different molar ratios of Co to $\mathrm{Mg}$ on the COD removal rate; effect of different initial concentrations of phenol on the COD removal rate; and effect of $\mathrm{Mg}(\mathrm{OH})_{2}$ catalytic ozonation on the COD of phenol wastewater; and (4) summary (PDF)

\section{AUTHOR INFORMATION}

\section{Corresponding Authors}

Lilong Zhou - College of Chemical and Pharmaceutical Engineering, Hebei University of Science and Technology, Shijiazhuang, Hebei 050018, P. R. China; (1) orcid.org/ 0000-0003-3745-501X; Email: lanruohe@126.com

Jimmy Yun - College of Chemical and Pharmaceutical Engineering, Hebei University of Science and Technology, Shijiazhuang, Hebei 050018, P. R. China; School of 
Chemical Engineering, The University of New South Wales, Australia, Sydney, NSW 2052, Australia; Tianjushi Engineering \& Technology Group Co., Ltd., Shijiazhuang, Hebei 050000, P. R. China; Email: jimmy.yun@ unsw.edu.au

\section{Authors}

Shanshan Zhang - College of Chemical and Pharmaceutical Engineering, Hebei University of Science and Technology, Shijiazhuang, Hebei 050018, P. R. China

Zhengjie Li - College of Chemical and Pharmaceutical Engineering, Hebei University of Science and Technology, Shijiazhuang, Hebei 050018, P. R. China

Ali Asghar Esmailpour - School of Chemical Engineering, The University of New South Wales, Australia, Sydney, NSW 2052, Australia

Kunjie Li - College of Chemical and Pharmaceutical Engineering, Hebei University of Science and Technology, Shijiazhuang, Hebei 050018, P. R. China

Shuhuan Wang - College of Chemical and Pharmaceutical Engineering, Hebei University of Science and Technology, Shijiazhuang, Hebei 050018, P. R. China

Runjing Liu - College of Chemical and Pharmaceutical Engineering, Hebei University of Science and Technology, Shijiazhuang, Hebei 050018, P. R. China

Xiaoyan Li - College of Textile and Garments, Hebei University of Science and Technology, Shijiazhuang, Hebei 050018, P. R. China

Complete contact information is available at:

https://pubs.acs.org/10.1021/acsomega.1c03497

\section{Author Contributions}

${ }^{\perp}$ S.Z. and L.Z. contributed equally to this work.

\section{Notes}

The authors declare no competing financial interest.

\section{ACKNOWLEDGMENTS}

The authors gratefully acknowledge financial support from the Youth Found of Education Department of Hebei Province (No. QN2019230), the Natural Science Foundation of Hebei Province Youth Project (No. B2019208333), and the Youth Projects of the National Natural Science Foundation of China (22005083).

\section{REFERENCES}

(1) Zhao, P.; Qi, Y.; Yang, Y. L. Treatment Technologies of Nondegradable Organic Wastewater. Sichuan Environ. 2006, 4, 98-103.

(2) Pi, Y.; Wang, J. Mechanism and reaction pathway of ozonation of 4-chlorophenol in water. Sci. China, Ser. B 2006, 36, 87-92.

(3) Pratarn, W.; Pornsiri, T.; Thanit, S. Adsorption and ozonation kinetic model for phenolic wastewater treatment. Chin. J. Chem. Eng. 2011, 19, 76-82.

(4) Chen, B.; Hu, Y.; Tao, W. Formation and Treatment Technology of Volatile Phenolic in Refinery Purifying Water. Technol. Dev. Chem. Ind. 2013, 4, 48-50.

(5) Turhan, K.; Uzman, S. Removal of phenol from water using ozone. Desalination. 2008, 229, 257-263.

(6) Lishman, L.; Shirley, A. S.; Kurtis, S. Occurrence and reductions of pharmaceuticals and personal care products and estrogens by municipal wastewater treatment plants in Ontario. Sci. Total Environ. 2006, 367, 544-558.

(7) Xie, Y. B.; Chen, Y. Y.; Yang, J. Distinct synergetic effects in the ozone enhanced photocatalytic degradation of phenol and oxalic acid with $\mathrm{Fe}^{3+} / \mathrm{TiO}_{2}$ catalyst. Chin. J. Chem. Eng. 2018, 26, 1528-1535.
(8) Dai, Q.; Wang, J.; Yu, J. Catalytic ozonation for the degradation of acetylsalicylic acid in aqueous solution by magnetic $\mathrm{CeO}_{2}$ nanometer catalyst particles. Appl. Catal., B 2014, 144, 686-693.

(9) Li, C.; Jiang, F.; Sun, D. Catalytic ozonation for advanced treatment of incineration leachate using $\left(\mathrm{MnO}_{2}-\mathrm{Co}_{3} \mathrm{O}_{4}\right) / \mathrm{AC}$ as a catalyst. Chem. Eng. J. 2017, 325, 624-631.

(10) Lu, J.; Sun, J. X.; Chen, X. X. Efficient mineralization of aqueous antibiotics by simultaneous catalytic ozonation and photocatalysis using $\mathrm{MgMnO}_{3}$ as a bifunctional catalyst. Chem. Eng. J. 2019, $358,48-57$.

(11) Wang, Y.; Yang, W. Z.; Yin, X. S. The role of Mn-doping for catalytic ozonation of phenol using $\mathrm{Mn} / \gamma-\mathrm{Al}_{2} \mathrm{O}_{3}$ nanocatalyst: Performance and mechanism. J. Environ. Chem. Eng. 2016, 4, 3415-3425.

(12) Esmailpour, A. A.; Moradi, S.; Yunb, J. Promoting Surface Oxygen Vacancies on Ceria via Light Pretreatment to Enhance Catalytic Ozonation. Catal. Sci. Technol. 2019, 9, 5979-5990.

(13) Moussavi, G.; Mahmoudi, M. Removal of azo and anthraquinone reactive dyes from industrial wastewaters using $\mathrm{MgO}$ nanoparticles. J. Hazard Mater. 2009, 168, 806-812.

(14) Zhu, H.; Ma, W. H.; Han, H. J. Catalytic ozonation of quinoline using nano-MgO: Efficacy, pathways, mechanisms and its application to real biologically pretreated coal gasification wastewater. Chem. Eng. J. 2017, 327, 91-99.

(15) Moussavi, G.; Mashayekh-Salehi, A.; Yaghmaeian, K. The catalytic destruction of antibiotic tetracycline by sulfur-doped manganese oxide (S-MgO) nanoparticles. J. Environ. Manage. 2018, 210, 131-138.

(16) Asgari, G.; Salari, M. Optimized synthesis of carbon-doped nano- $\mathrm{MgO}$ and its performance study in catalyzed ozonation of humic acid in aqueous solutions: Modeling based on response surface methodology. J. Environ. Manage. 2019, 239, 198-210.

(17) Chen, Y.; Wu, Y.; Liu, C. Low-temperature conversion of ammonia to nitrogen in water with ozone over composite metal oxide catalyst. J. Environ. Sci. 2018, 66, 265-273.

(18) Moussavi, G.; Rashidi, R.; Khavanin, A. The efficacy of GAC/ $\mathrm{MgO}$ composite for destructive adsorption of benzene from waste air stream. Chem. Eng. J. 2013, 228, 741-747.

(19) Scorza, E.; Birkenheuer, U.; Pisani, C. The oxygen vacancy at the surface and in bulk MgO: an embedded cluster study. J. Chem. Phys. 1997, 107, 9645-9658.

(20) Rezaei, F.; Moussavi, G.; Bakhtiari, A. R. Toluene removal from waste air stream by the catalytic ozonation process with $\mathrm{MgO} / \mathrm{GAC}$ composite as catalyst. J. Hazard. Mater. 2016, 306, 348-358.

(21) Moussavi, G.; Aghapour, A. A.; Yaghmaeian, K. The degradation and mineralization of catechol using ozonation catalyzed with $\mathrm{MgO} / \mathrm{GAC}$ composite in a fluidized bed reactor. Chem. Eng. J. 2014, 249, 302-310.

(22) Chen, J.; Tian, S. H.; Lu, J. Catalytic performance of $\mathrm{MgO}$ with different exposed crystal facets towards the ozonation of 4chlorophenol. Appl. Catal., A 2015, 506, 118-125.

(23) Jia, Y. C.; Wang, S. Y.; Lu, J. Q. Effect of Structural Properties of Mesoporous $\mathrm{Co}_{3} \mathrm{O}_{4}$ Catalysts on Methane Combustion. Chem. Res. Chin. Univ. 2016, 32, 808-811.

(24) Turhan, K.; Uzman, S. Removal of phenol from water using ozone. Desalination 2008, 229, 257-263.

(25) Karim, A. M.; Su, Y.; Engelhard, M. H.; King, D. L.; Wang, Y. Catalytic Roles of $\mathrm{Co}^{0}$ and $\mathrm{Co}^{2+}$ during Steam Reforming of Ethanol on $\mathrm{Co} / \mathrm{MgO}$ Catalysts. ACS Catal. 2011, 1, 279-286.

(26) Yan, F. G.; Huang, J. C.; Ling, G. S. Study on the Effect of Acetic Acid on the Light Burned Magnesia Hydration. J. Salt Sci. Chem. Ind. 2019, 1, 10-15.

(27) Brunauer, S.; Deming, L.; Teller, W. On a theory of the van der waals adsorption of gases. J. Am. Chem. Sci. 1940, 62, 1723-1732.

(28) Zhang, X. F.; Shen, T. D.; Ding, Y. L. Graphite Felt Supported $\mathrm{MgO}$ Catalytic Ozonation of Bisphenol A. Ozone: Sci. Eng. 2019, 41, 541-550. 
(29) Shen, T. D.; Wang, Q. W.; Tong, S. P. Solid Base MgO/ Ceramic Honeycomb Catalytic Ozonation of Acetic Acid in Water. Ind. Eng. Chem. Res. 2017, 1-30.

(30) Afzal, S.; Quan, X.; Lu, S. Catalytic performance and an insight into the mechanism of $\mathrm{CeO}_{2}$ nanocrystals with different Characterization Methods. Appl. Catal., B 2019, 248, 526-537.

(31) Dubecký, F.; Kindl, D.; Hubík, P. A comparative study of $\mathrm{Mg}$ and Pt contacts on semi-insulating GaAs: Electrical and XPS characterization. Appl. Surf. Sci. 2017, 395, 131-135.

(32) Li, C. H.; Jiang, F.; Sun, D. Z. Catalytic ozonation for advanced treatment of incineration leachate using $\left(\mathrm{MnO}_{2}-\mathrm{Co}_{3} \mathrm{O}_{4}\right) / \mathrm{AC}$ as a catalyst. Chem. Eng. J. 2017, 325, 624-631.

(33) Luo, Y. J.; Zheng, Y. B.; Zuo, J. C. Insights into the high performance of $\mathrm{Mn}$-Co oxides derived from metalorganic frameworks for total toluene oxidation. J. Hazard. Mater. 2018, 349, 119-127.

(34) Feng, Y. J.; Li, L.; Niu, S. F. Controlled synthesis of highly active mesoporous $\mathrm{Co}_{3} \mathrm{O}_{4}$ polycrystals for low temperature $\mathrm{CO}$ oxidation. Appl. Catal., B 2012, 111-112, 461-464.

(35) Li, B.; Li, L. W.; Dong, Y. N. Glucose Isomerization into Fructose Catalyzed by $\mathrm{MgO} / \mathrm{NaY}$ Catalyst. Chin. J. Chem. Phys. 2018, 31, 203-210.

(36) Chen, J.; He, X.; Zhao, H. Research on treatment properties of azo dye wastewater with catalytic ozonation by iron magnesium composite oxide. J. Bengbu Univ. 2018, 2, 28-32.

(37) Huang, Y. X.; Cui, C. C.; Zhang, D. F. Heterogeneous catalytic ozonation of dibutyl phthalate in aqueous solution in the presence of iron-loaded activated carbon. Chemosphere 2015, 119, 295-301.

(38) Moussavi, G.; khavanin, A.; Alizadeh, R. The integration of ozonation catalyzed with $\mathrm{MgO}$ nanocrystals and the biodegradation for the removal of phenol from saline wastewater. Appl. Catal., B 2010, 97, 160-167.

(39) Zhu, J. B.; Zhuang, X. Y.; Tong, D. S. Preparation of Magnesium Oxide and Its Application in Catalysis; Zhejiang Chemical Industry, 2017; Vol. 48. 